\title{
DESENVOLVIMENTO E VALIDAÇÃO DE UM INSTRUMENTO PARA MAPEAR E AVALIAR COMPETÊNCIAS NO PROCESSO DE ENSINO-APRENDIZAGEM DE LÍNGUA ESPANHOLA
}

\author{
Franciane de Araújo Soares - IFAM - franciane.soares@ gmail.com \\ Iandra Maria Weirich da Silva Coelho - IFAM - iandra.coelho@ifam.edu.br
}

\begin{abstract}
Resumo: Neste artigo, é apresentado o processo de construção e validação de um instrumento para mapear e avaliar competências relacionadas ao processo de ensinoaprendizagem de Língua Espanhola. O estudo foi desenvolvido em três etapas: definição do construto teórico, com base em um levantamento bibliográfico e documental; elaboração e validação do instrumento, com ênfase na avaliação da pertinência, clareza, semântica e representatividade dos itens. Os procedimentos metodológicos incluem uma abordagem quantitativa, com análise de frequência de palavras para elaboração dos itens de avaliação e qualitativa. O instrumento mostra-se relevante para auxiliar na coleta de informações que podem contribuir para a identificação das necessidades e dificuldades dos estudantes, com relação à aquisição e desenvolvimento de saberes, habilidades e atitudes referentes ao uso da língua-alvo.
\end{abstract}

Palavras-chave: Avaliação; Instrumentos; Competência; Língua Espanhola.

\section{Development and validation an instrument to map and evaluate competences in the Spanish language teaching-learning process}

\begin{abstract}
In this research, is presented the process of construction and validation of an instrument to map and evaluate competences related to the teaching-learning process of Spanish Language. The research was developed in the three stages: definition of the theoretical construct, based on a bibliographical and documentary survey; elaboration and validity of the instrument, with emphasis on the evaluation of the pertinence, clarity, semantics and representativeness of the items. The methodological procedures include a quantitative approach, with word frequency analysis for the preparation of evaluation and qualitative items. The instrument is relevant, to assist in the collection of information that can contribute to the identification of students' needs and difficulties, in relation to the acquisition and development of competences, skills and attitudes regarding the use of the target language.
\end{abstract}

Keywords: Evaluation; Instruments; Competence; Spanish language.

\section{Considerações Iniciais}

Este artigo tem como objetivo principal apresentar o desenho e validação de um instrumento criado para o mapeamento das competências comunicativa e digital necessárias no processo de ensino-aprendizagem de Língua Espanhola (doravante LE) e coleta de informações relacionadas ao desenvolvimento de conhecimentos, habilidades e atitudes que compreendem tais competências, tendo o meio virtual como potencial meio de comunicação, na qual os estudantes manifestam diferentes interesses e estão motivados a buscar novos conhecimentos e conectar-se com outras pessoas.

Por tal motivo, essa proposta justifica-se pela necessidade de buscar ferramentas que permitem diagnosticar as dificuldades encontradas pelos estudantes, 
com relação ao uso da língua em diferentes contextos de comunicação, especialmente on-line.

De acordo com a literatura especializada, estas competências são fundamentais para a atuação na sociedade, que implica no uso crítico e seguro das Tecnologias da Informação e Comunicação (doravante TIC) para o trabalho, o ócio e as interações comunicativas (Area Moreira, 2012; Intef, 2017).

Uma vez identificada as competências aqui tratadas, destaca-se a principal motivação deste estudo que surgiu das inquietações e experiências obtidas ao longo das trajetórias acadêmico-profissionais das pesquisadoras como docentes de LE. Por meio destas vivências, foram identificadas dificuldades relacionadas a situações de ensinoaprendizagem que ocorrem nos contextos digitais, como por exemplo, iniciar ou manter interações comunicativas com falantes nativos, bem como realizar atividades didáticas com o uso das TIC.

Nesse cenário, justifica-se a coleta de evidências para a avaliação do desenvolvimento de competências relacionadas à comunicação na língua-alvo, a fim de auxiliar estudantes e professores no diagnóstico e análise de dados referentes às dificuldades e necessidades de aprendizagem dos estudantes, do uso das TIC para a realização das tarefas comunicativas, das práticas e metodologias empregadas, bem como contribuir para o estado da arte sobre a temática de competências.

Os procedimentos metodológicos adotados envolvem três etapas: organização do construto teórico, por meio da realização de um levantamento bibliográfico e documental acerca das competências mencionadas; a elaboração e a validação do instrumento, com ênfase na avaliação da pertinência, clareza, semântica e a representatividade dos itens, através de uma análise realizada por um grupo de juízes.

Faz parte da etapa inicial, o estudo de documentos oficiais, tanto no âmbito nacional, com a Base Nacional Comum Curricular (Brasil, 2017), como internacional, que compreende marcos de referência e um arcabouço teórico que envolve estudos sobre as competências comunicativa e digital.

Este artigo está dividido em quatro seções que incluem as referências teóricas e os procedimentos metodológicos para a elaboração e validação do instrumento, seguidas pelas considerações finais e referências utilizadas.

\section{O conceito de competências: comunicativa e digital}

Essa seção, inicialmente, trata dos conceitos de competências comunicativa e digital. De maneira geral, a competência é como um "conjunto de atitudes, aptidões, capacidades, habilidades e conhecimentos que habilitam o sujeito para vários desempenhos da vida" (Konrath; Tarouco; Behar, 2009). Para Zabala e Arnau (2010), a competência é tratada como a capacidade ou a habilidade para realizar tarefas ou atuar frente a situações diversas, de forma eficaz em um determinado contexto. Dessa forma faz-se necessário mobilizar recursos, tais como conhecimentos, habilidades e atitudes.

O conceito de competência comunicativa criado por Hymes (1972) compreende a capacidade de uso da língua e faz referência não apenas aos aspectos linguísticos, mas também os sociais e sociolinguísticos. Nesse sentido, o objetivo da competência "é mostrar as formas em que o sistematicamente possível, o factível e o apropriado se unem para produzir e interpretar a conduta cultural que de fato ocorre" (Hymes, 1972), aproximando-se dos diferentes aspectos da língua em condições de uso real.

Nesse contexto, a competência comunicativa é compreendida como um conjunto de componentes linguísticos, sociolinguísticos e pragmáticos, relacionados aos 
conhecimentos e habilidades necessárias ao processamento da comunicação (Conselho da Europa, 2001), visando ao uso em situações socioculturais reais. Dessa forma, caracteriza-se por compreender "não só a habilidade de produzir e interpretar expressões linguísticas, mas também a habilidade de interagir socialmente com a língua" (Bernabé, 2017, p.05).

No que se refere à competência digital, para Ferrari (2012) a definição está relacionada a um

\begin{abstract}
[...] conjunto de conhecimentos, habilidades, atitudes (incluindo, portanto, habilidades, estratégias, valores e consciência) que são necessários ao usar as TIC e meios de comunicação digitais para executar tarefas; resolver problemas; comunicar; gerenciar informações; colaborar; criar e compartilhar conteúdo; e construir o conhecimento de forma eficaz, eficiente, crítica, criativa, autônoma, flexível, ética, reflexiva para o trabalho, o lazer, a participação, a aprendizagem, a socialização. (Ferrari, 2012, p. 3-4)
\end{abstract}

No século da informação rápida e da comunicação instantânea, a competência digital é essencial e transversal à aquisição de todas as outras, evidenciando a relevância da aquisição e desenvolvimento dessa competência, a fim de potencializar a interação comunicativa em contextos virtuais.

\title{
O uso das TIC e o desenvolvimento de competências no processo de ensino- aprendizagem de línguas
}

Os novos desafios do século XXI e as constantes e complexas mudanças ocorridas no contexto social evidenciam a necessidade de novas práticas educativas, levando em conta o potencial uso das TIC no acesso às informações e a facilidade na comunicação. Nesse cenário, destaca-se a relevância da aprendizagem de outros idiomas, no sentido de ampliar as possibilidades de comunicação e trocas culturais entre aprendizes e pessoas de outros países, bem como fomentar os intercâmbios e a internacionalização. Isso implica no efetivo uso da língua em diferentes situações comunicativas, orais ou escritas, por meio de redes sociais, vídeo-chamadas, webconferências, e-mails etc, motivado, principalmente, pela necessidade de interação e troca de informações.

Nesse âmbito, o uso das TIC no ensino de LE pode potencializar novas formas de comunicação e trabalho, além de propiciar ao estudante uma imersão linguística, facilitada por diversos canais que fomentam as trocas e colaborações proporcionadas pelo acesso às informações na língua-alvo; interação comunicativa; execução de trabalhos colaborativos; criação e compartilhamento de conteúdos digitais adaptados e/ou autorais em LE (apresentações, textos, imagens, vídeos, entre outros), entre outras possibilidades.

Levando em conta tais possibilidades, nesse estudo, destacam-se duas competências indispensáveis, tanto na sociedade como no âmbito educacional - a comunicativa e a digital - uma vez que a comunicação não depende apenas de fatores geográficos ou temporais, e o uso de diferentes recursos, advindos com a Internet, tais como, redes sociais (blog, sites, Facebook, Twitter, Instagram), aplicativos e correios eletrônicos, entre outros, tem se intensificado nas instituições de ensino.

Cabe ressaltar que essa seleção não é aleatória. No contexto europeu, estas competências são citadas entre as oito competências-chave para a aprendizagem permanente: comunicação em línguas estrangeiras e competência digital (Parlamento Europeu e Conselho da União Europeia, 2006). Igualmente ocorre no contexto brasileiro, em que ambas competências também fazem parte da Base Nacional Comum 
Curricular (Brasil, 2017), documento que ressalta o desenvolvimento de dez competências gerais que os estudantes devem aprender ao longo da Educação Básica. Nesse documento, as competências são denominadas respectivamente como comunicação e cultura digital, e consideradas competências gerais atribuídas a todas as áreas.

No que tange ao ensino de línguas, esse cenário evidencia a importância do planejamento, criação e aplicação de instrumentos de avaliação que possam auxiliar professores e estudantes de línguas, no ensino, aprendizagem e mapeamento das competências a serem desenvolvidas durante o processo, no sentido de potencializar a coleta e identificação de evidências para acompanhamento do processo.

Em seguida, na próxima seção, evidenciam-se os procedimentos metodológicos adotados para a construção de um instrumento criado para o mapeamento e avaliação das competências necessárias no processo de ensino-aprendizagem de LE (doravante IMAC).

\section{Procedimentos metodológicos: Elaboração do instrumento}

Este estudo, de caráter exploratório e descritivo, está dividido em três etapas, que envolvem o levantamento bibliográfico da literatura especializada, a elaboração e a validação do instrumento.

A etapa de composição do construto teórico compreende o planejamento, desenho e desenvolvimento do IMAC. Essa etapa conta com uma revisão bibliográfica e documental. A base teórico-metodológica foi composta por estudos, dissertações, artigos, marcos de referências e documentos oficiais que têm como foco a competência comunicativa e digital, encontrados em diferentes bases de dados, Scielo, Dialnet, Google Acadêmico e IBICT (BDTD). Além dessas bases, faz parte da revisão, livros e materiais impressos diversificados, que inclui o uso de mapas conceituais, rubricas e outros instrumentos para avaliação de competências.

Essa literatura foi organizada num portfólio bibliográfico, sintetizado no Quadro 1, que serviu como amostra para elaboração do mapeamento das competências e identificação dos principais critérios avaliados referentes a cada competência.

Quadro 1- Portfólio bibliográfico para construção do instrumento avaliativo

\begin{tabular}{|l|l|}
\hline $\begin{array}{l}\text { Competência } \\
\text { Comunicativa }\end{array}$ & $\begin{array}{l}\text { Conselho da Europa (2001); Organización para la Cooperación y el Desarrollo Económico, } \\
\text { (2005); Nagamine; Braga (2008), Barbero Andrés et al. (2008); Illera e Roig (2010); Jara e } \\
\text { Cabrera (2012); García et al. (2015); Bernabé (2017). }\end{array}$ \\
\hline $\begin{array}{l}\text { Competência } \\
\text { Digital }\end{array}$ & $\begin{array}{l}\text { Organización para la Cooperación y el Desarrollo Económico (2005); Parlamento Europeu } \\
\text { e Conselho (2006); Spressola (2010); Vivancos (2010); Area Moreira (2012); Ferrari (2012) } \\
\text { Schineder (2014); Marco Común de Competencia Digital docente (INTEF, 2017); Lucas; } \\
\text { Moreira (2017). }\end{array}$ \\
\hline
\end{tabular}

Consideradas as competências desse estudo, foi realizada uma análise da amostra compilada, visando à elaboração dos itens, referentes à produção, recepção e interação na língua-alvo, nas modalidades oral e escrita, em contextos on-line ou híbridos, que abrange o ensino-aprendizagem presencial e virtual.

Dessa forma, tendo como base as duas competências gerais: comunicativa e digital, foi realizado um levantamento das competências específicas (Zabala; Arnau, 2010) mais frequentes. O desenvolvimento destas competências leva em conta uma proposta de ensino, aprendizagem e avaliação com foco no desenvolvimento de saberes, habilidades e atitudes envolvidas nas ações comunicativas e uso de LE em contextos virtuais de comunicação. 
Por meio de uma análise quantitativa, foram identificadas as categorias de produção e interação, como as mais frequentes na amostra referente à competência comunicativa. Por outro lado, a busca, acesso, criação e compartilhamento de informações e conteúdos foram as categorias de maior frequência na amostra referente à competência digital. A junção desses elementos constituiu a categorização de três competências, consideradas específicas e necessárias para a atuação dos estudantes nos ambientes virtuais: i) interação na língua-alvo por meio das tecnologias digitais; ii) criação de conteúdos digitais na língua-alvo; e iii) compartilhamento de conteúdos na língua-alvo.

A próxima etapa, referente à elaboração do instrumento, também contou com uma análise qualitativa das amostras compiladas, realizada com auxílio do software de análise Sphinx (Freitas et al., 2008), que permitiu a realização do mapeamento das competências, seleção e avaliação dos itens a serem inseridos no instrumento.

Nesse processo, os itens foram organizados em forma de um questionário e o mapeamento foi realizado por meio da identificação de conhecimentos, habilidades e atitudes. Na identificação dessas categorias, os conhecimentos fazem referência aos fatos, conceitos e sistemas conceituais, tais como o saber conceitual; as habilidades são de caráter prático, técnico ou procedimental e referem-se a um recurso aplicado a situações conhecidas e rotineiras e as atitudes podem fazer a diferença na resolução de problemas ou enfrentamento das situações, bem como ser observadas por meio da aplicação das habilidades e dos conhecimentos, em formato de ações, dos comportamentos e das posturas (Behar, 2013).

Essa organização inicial dos elementos também teve como base orientações e modelos de instrumentos de construtos semelhantes (Pasquali, 1999 citado por Mendonça; Guerra, 2007; Spressola, 2010; Schneider, 2014; Intef, 2017).

Inicialmente, foram elencados cem (100) itens (proposições) que evidenciam a comunicação em LE e o uso das TIC, tomando como base as três competências específicas para o uso comunicativo da língua em contextos virtuais. No segundo momento, com intuito de agrupar itens semelhantes, a lista foi organizada em sessenta e dois (62) itens.

\section{Validação do instrumento}

Para o processo de validação do instrumento foi realizada uma avaliação definida pela sequência: elaboração do instrumento e avaliação dos juízes (Alexandre; Coluci, 2011; Bellucci; Matsuda, 2012; Oliveira et al., 2014).

Considerando que a validade e confiabilidade são requisitos essenciais para a validação de um instrumento, neste processo a confiabilidade de consistência interna está relacionada à semelhança das respostas dos juízes, enquanto a validade associa-se ao grau de certeza sobre o conceito medido. O procedimento de validação do instrumento refere-se à validade interna dos resultados apresentados, com o intuito de que os resultados não sofram qualquer interferência do pesquisador. Esses procedimentos levam em conta os mecanismos para a confiabilidade da coleta.

Para realizar tal validação, o instrumento foi encaminhado a um comitê de juízes para avaliação dos itens. O comitê foi formado por seis (6) especialistas, oriundos de diferentes regiões do país, professores da área de ensino de LE. São mestres e doutores, com experiência no ensino de Espanhol e com o uso das TIC, dois (02) especialistas na área das competências (doutor e doutorando) e um (01) profissional da área de Letras, Língua Portuguesa, para realização da avaliação semântica dos itens do instrumento. Cabe ressaltar que na literatura não há um número exato de avaliações 
necessárias para a validade. Segundo Alexandre e Coluci (2011, p. 3064), para "essa decisão deve-se levar em conta as características do instrumento, a formação, a qualificação e a disponibilidade dos profissionais necessários".

O objetivo do comitê foi avaliar as competências, bem como seus respectivos elementos. Em síntese, a avaliação tem como foco uma análise relacionada à pertinência (relevância e representatividade) e à clareza (inteligível pelo leitor) de cada item, a fim de determinar a permanência ou exclusão dos itens no instrumento. Para avaliar a representatividade do item, foi utilizada uma escala tipo Likert, com pontuação de um a quatro: 1. Não relevante; 2 . Necessita de grande revisão para ser relevante; 3. Necessita de pequena revisão para ser relevante; 4 . Relevante.

Após as considerações dos especialistas, a próxima etapa realizada foi a verificação da confiabilidade do instrumento, verificada por meio da porcentagem de concordância das respostas de pertinência e clareza com relação a cada item. Para avaliar a concordância na validação de conteúdo, a medida empregada foi o percentual de concordância $(\%$ concordância $=$ número de participantes que concordaram totalmente com o item/número total de participantes x 100), indicada pela fórmula ilustrada abaixo:

$$
\text { média \% concordância }=\frac{\text { número de participantes que concordaram }}{\text { número total de participantes }} \times 100
$$

Segundo Pasquali (2003), a taxa de porcentagem válida para análise da concordância de instrumentos psicométricos deve ser acima de $80 \%$, isto é, os avaliadores devem concordar em sua maioria que aquele item é relevante. Dessa forma, apenas os itens com mais de $80 \%$ de concordância nos score 3 e 4 (Necessita de pequena revisão para ser relevante e Relevante) permaneceram no instrumento.

A partir desses resultados, dos comentários dos avaliadores, foi realizada a depuração dos conteúdos. Nesse processo foram excluídos vinte e um (21) itens e a partir das sugestões dos juízes houve a reescrita e exclusão de itens com problemas quanto à clareza; mudança de vocábulos; adequação dos verbos dos elementos das competências com relação ao campo semântico; repetições; combinação de itens ou eliminação, com intuito de deixar o instrumento mais coerente e completo.

Na Figura 1, apresenta-se uma síntese das informações referentes ao construto teórico-metodológico adotado para a criação e desenvolvimento do IMAC e os passos seguidos para sua elaboração e validação.

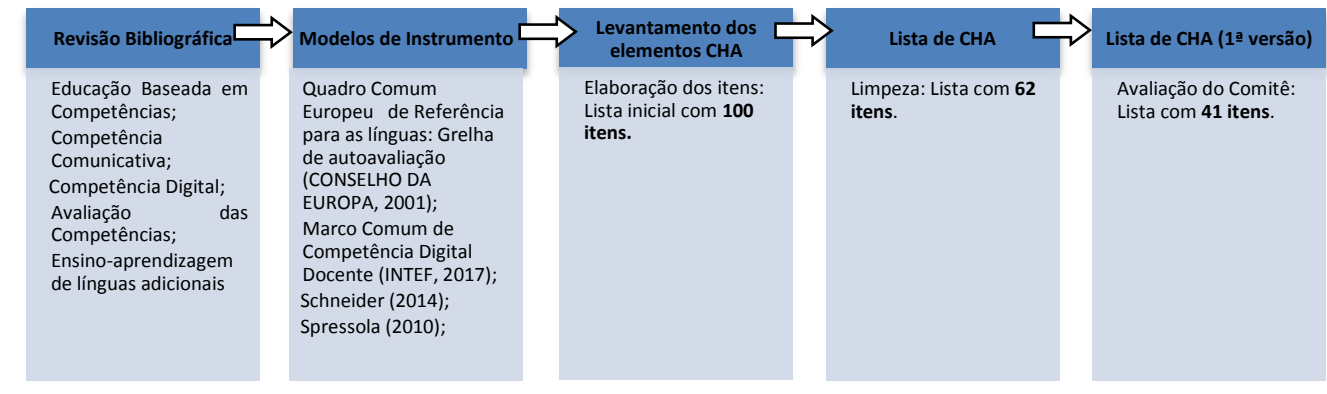

Figura 1- Construto teórico-metodológico adotado para o instrumento

Com base nesses procedimentos, o instrumento final compreende três blocos, relacionados a cada uma das competências elucidadas, e conta com quarenta e um (41) itens que fazem referência aos saberes, habilidades e atitudes referentes ao uso da língua, acerca do processo interativo em LE, da criação de conteúdos digitais voltados para a aprendizagem e do compartilhamento de informações. No Quadro 2, apresenta- 
se, a modo de ilustração, parte desse instrumento com referência à competência interação em LE por meio das TIC.

Quadro 2 - Interação em LE por meio das TIC

\begin{tabular}{|c|c|}
\hline \multicolumn{2}{|r|}{ INTERAÇÃO EM LE POR MEIO DAS TIC } \\
\hline \multirow{6}{*}{ 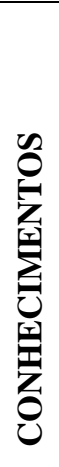 } & $\begin{array}{l}\text { Reconheço vocabulário e estruturas gramaticais da língua-alvo como um dos elementos do processo } \\
\text { comunicativo (Conselho da Europa, 2001). }\end{array}$ \\
\hline & Tenho conhecimento da variação linguística em Língua Espanhola (Conselho da Europa, 2001). \\
\hline & $\begin{array}{l}\text { Compreendo textos escritos e orais em Língua Espanhola disponibilizados pelos meios digitais no } \\
\text { âmbito de minha área de atuação (Conselho da Europa, 2001). }\end{array}$ \\
\hline & $\begin{array}{l}\text { Reconheço o registro (linguagem/tratamento) formal e informal, adequado à situação e aos } \\
\text { interlocutores, para exercer funções comunicativas de acordo com a interação. }\end{array}$ \\
\hline & $\begin{array}{l}\text { Compreendo o funcionamento da língua, bem como suas normas e regras de conduta/uso, as netiquetas, } \\
\text { na comunicação virtual. }\end{array}$ \\
\hline & $\begin{array}{l}\text { Conheço as ferramentas de colaboração on-line, sites e plataformas, que servem como redes sociais } \\
\text { educativas ou que facilitam a comunicação e a interação oral e escrita em Língua Espanhola. }\end{array}$ \\
\hline \multirow{6}{*}{ 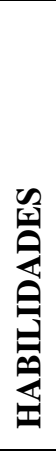 } & $\begin{array}{l}\text { Interajo realizando práticas orais e escritas por meio das redes sociais e/ou ambientes virtuais de } \\
\text { aprendizagem com falantes nativos, quando presentes, e não nativos para praticar a língua-alvo. }\end{array}$ \\
\hline & $\begin{array}{l}\text { Articulo expressões escritas e/ou orais sobre experiências, acontecimentos, sonhos, desejos, ambições, } \\
\text { família, pessoas e condições de vida utilizando a Língua Espanhola (Conselho da Europa, 2001). }\end{array}$ \\
\hline & $\begin{array}{l}\text { Expresso-me oralmente por recursos digitais: vídeos, mensagens instantâneas, chats, entre outros, por } \\
\text { meio da língua espanhola. }\end{array}$ \\
\hline & $\begin{array}{l}\text { Acesso informação em Língua Espanhola por meio de conteúdos digitais, arquivos, fotos, vídeos, entre } \\
\text { outros compartilhados na interação (Intef, 2017). }\end{array}$ \\
\hline & $\begin{array}{l}\text { Uso a língua, os símbolos, os textos, a informação, o conhecimento e as TIC de maneira interativa no } \\
\text { contexto dos falantes de espanhol. (Ocde, 2005). }\end{array}$ \\
\hline & Protejo-me de possíveis perigos na rede (Intef, 2017). \\
\hline \multirow{6}{*}{$\frac{\sqrt[n]{5}}{2}$} & $\begin{array}{l}\text { Estou dispost@/abert@ a trocar mensagens, estabelecer contatos e comunicar-me com falantes da } \\
\text { língua-alvo por meio das TIC (Vivancos, 2010). }\end{array}$ \\
\hline & $\begin{array}{l}\text { Disponho-me a procurar e experimentar novas ferramentas de comunicação on-line sempre com o } \\
\text { objetivo e a motivação de melhorar meu processo de aprendizagem. }\end{array}$ \\
\hline & $\begin{array}{l}\text { Reflito sobre as próprias necessidades nos âmbitos comunicativo e digital para a interação em LE } \\
\text { (Conselho da Europa, 2001). }\end{array}$ \\
\hline & $\begin{array}{l}\text { Adoto uma conduta respeitosa com os interlocutores de forma escrita e oral, tais como, professor, } \\
\text { colegas e outros que participam da comunicação on-line. (Barbero Andrés, 2008). }\end{array}$ \\
\hline & $\begin{array}{l}\text { Mostro-me atento e criterioso para avaliar a qualidade, propriedade e o valor da informação, igualmente } \\
\text { suas fontes. }\end{array}$ \\
\hline & $\begin{array}{l}\text { Interesso-me por estabelecer contatos e comunicar-me com falantes da língua-alvo por meio das TIC } \\
\text { (Vivancos, 2010). }\end{array}$ \\
\hline
\end{tabular}

Esse instrumento, compilado em formato de um questionário, pode ser utilizado para realizar uma autoavaliação, em que os estudantes identificam suas necessidades e a frequência de uso das TIC. O diagnóstico compreende uma escala de tipo Likert, contendo as seguintes opções: (1) Nunca aplico; (2) Ocasionalmente aplico; (3) Frequentemente aplico; e (4) Desconheço.

O diagnóstico visa favorecer a autoavaliação por parte do estudante para que ele possa identificar necessidades referentes à aquisição e desenvolvimento de competências, assim como possibilitar uma participação ativa. Vale ressaltar que a autoavaliação é parte do ensino e da aprendizagem, considerando-se o estudante como um elemento ativo e responsável na avaliação, tornando-o mais consciente, crítico e promovendo maior autonomia na regulação do processo de aprendizagem. Além disso, representa um fator motivacional, visto que não há fato mais decisivo no desenvolvimento psicológico humano do que a avaliação de si mesmo (Castillo Arrendo; Cabrerizo Diago, 2010). Além disso, a autoavaliação auxilia o professor a 
pontuar as ações realizadas pelo estudante ao final ou ao longo de um curso (Fernández, 2011).

Essa avaliação pode ser realizada em qualquer fase do processo de ensinoaprendizagem, início, meio ou fim, conforme os objetivos do professor. Por exemplo, antes de iniciar as aulas o professor pode disponibilizá-lo para diagnosticar as competências necessárias a serem desenvolvidas, bem como identificar saberes, habilidades e comportamentos referentes ao uso da língua de maneira individual ou coletiva, servindo como evidências acerca das aprendizagens a serem alcançadas. Nesse sentido, "los resultados esperados se hacen explícitos: son de conocimiento público, conocidos y acordados por los alumnos y el profesor de modo que los estudiantes sepan qué competencias se espera que ellos desarrollen". (García et al., 2015, p. 149)

A identificação destes aspectos pode permitir autorregular informações e indicadores do desempenho eficiente dos estudantes no uso efetivo da língua, no intercâmbio de ideias, na criação, produção e recepção de distintas atividades da língua, de ações, comportamentos, trocas de experiências e distintas interações discursivas e socioculturais. Dessa forma, identificar tais informações pode auxiliar o professor no sentido de melhoria de suas práticas, planejamento e execução de atividades na línguaalvo, que possibilitem aos estudantes potencializar e desenvolver suas competências, visando à melhoria educativa a partir dos resultados.

Cabe ainda ressaltar que apesar de estar direcionado a Língua Espanhola, é possível ser aplicado para outros idiomas que tenham suas práticas pedagógicas consolidadas num trabalho que envolve o ensino da língua-alvo, com ênfase na comunicação oral e escrita nos meios digitais.

\section{Considerações Finais}

Este artigo teve como objetivo apresentar um instrumento criado para o mapeamento e avaliação das competências relacionadas ao ensino-aprendizagem de LE, com foco principal no uso da língua oral e escrita em contextos virtuais, na criação de conteúdos digitais em LE e no compartilhamento de informações em LE. Nesse sentido, espera-se que as discussões e resultados apresentados do processo de elaboração e validação desse instrumento possam auxiliar professores e estudantes na identificação das necessidades referentes ao uso comunicativo da língua, integrado ao uso das TIC em diferentes contextos e possibilitem novas práticas pedagógicas.

Espera-se que o IMAC possa contribuir no sentido de suscitar novas pesquisas e discussões sobre o mapeamento e avaliação de competências, além de possibilitar um recurso que possa colaborar com o processo de ensinagem de LE, assim como outros idiomas, servindo como possível referência a ser usada como critérios de avaliação adotados na elaboração de outros instrumentos avaliativos, tais como as rubricas, por exemplo.

Em suma, objetiva-se continuar investigando sobre a temática das competências comunicativas e digitais da LE que podem ser utilizadas no processo de ensino-aprendizagem, e em pesquisas análogas, vislumbrando a criação e validação de novos instrumentos avaliativos. 


\section{Referências Bibliográficas}

AREA MOREIRA, Manuel. La alfabetización en la sociedad digital. In: Alfabetización digital y competencias informacionales. Colección Fundación Telefónica. Espanha: Editorial Ariel, 2012, p. 3-40.

ALEXANDRE, Neusa Maria Costa. COLUCI, Marina Zambon O. Validade de conteúdo nos processos de construção e adaptação de instrumentos de medidas. Base Scielo, 2011. Disponível em: http://www.scielo.br/pdf/csc/v16n7/06.pdf. Acesso em: 01 fev. 2018.

BARBERO ANDRÉS, J. et al. Las competencias básicas en el área de Lenguas Extranjeras. Cuadernos de Educación de Catábria. Cantabria: Consejería de Educación de Cantabria, 2008.

BEHAR, Patrícia A. Competências em educação a distância. Porto Alegre: Penso, 2013.

BELLUCCI JÚNIOR, José Aparecido; MISUE MATSUDA, Laura. Construção e validação de instrumento para avaliação do Acolhimento com Classificação de Risco. Revista brasileira de enfermagem, v. 65, n. 5, 2012. Disponível em: https://www.redalyc.org/html/2670/267025266006/. Acesso em 02 fev. 2018.

BERNABÉ, Flávia Herker Lopes. A COMPETÊNCIA COMUNICATIVA NO ENSINO DE LÍNGUAS ESTRANGEIRAS. Revista CBTecLE, v. 1, n. 1, p. 102-127, 2017.

BRASIL. Secretaria de Educação Básica. Ministério da Educação. Orientações Curriculares para o Ensino Médio - Linguagens, códigos e suas tecnologias. Brasília, 2006.

CASTILLO ARRENDO, S.; CABRERIZO DIAGO, J. Evaluación educativa de aprendizajes y competencias. Madri: Pearson, 2010.

CONSELHO DA EUROPA. Quadro Europeu Comum de Referência para as línguas: Aprendizagem, ensino, avaliação. Porto: Asa Editores, 2001.

FERNÁNDEZ, Sonsoles. La autoevaluación como estrategia de aprendizaje. MarcoELE Revista de Didáctica Español Lengua Extranjera. 2011.

FERRARI, A. Digital competence in practice: an analysis of frameworks. Sevilha: JRC-IPTS. 2012

FREITAS, Henrique; et al. Sphinx aprendiz. Canoas: Sphinx, 2008.

GARCÍA, Rosario Yanes et al. El aprendizaje del español basado en competencias: una opción para estudiantes no hispanohablantes. EDUMECENTRO, Santa Clara, v. 7, n. 3, p. 148-164, set. 2015.

HYMES, Dell Hathaway; On Communicative Competence. In PRIDE, J. B. e HOLMES, J. Sociolinguistics. Inglaterra: Penguin Books, 1972. Tradução de BERNAL, Juan Gómez. Acerca de la competencia comunicativa. Forma y función, n. 9, p. 13-37, 1996.

INTEF. Marco Común de Competencia Digital docente. Espanha, 2017. Disponível em: http://educalab.es/documents/10180/12809/MarcoComunCompeDigiDoceV2.pdf. Acesso em: 10 jan. 2018. 
JARA, Ana.; CABRERA, Anita. Mejoramiento de la competencia comunicativa en español como lengua extranjera a través de la videocomunicación. RLA, 50 (1), Chile, 2012, p. 139-160.

KONRATH, M. L. P.; TAROUCO, L. M. R.; BEHAR, P. A., Competências: desafios para alunos, tutores e professores da EaD. RENOTE, v.07, n.1, p. 1-10, 2009.

LUCAS, M.; MOREIRA, A. DigComp 2.1: Quadro Europeu de Competência Digital para Cidadãos: com oito níveis de proficiência e exemplos de uso. Aveiro: UA, 2017.

MENDONÇA, K. M. P. P.; GUERRA, R.O. Desenvolvimento e validação de um instrumento de medida da satisfação do paciente com a fisioterapia. Revista Brasileira de Fisioterapia. São Carlos: 2007. Disponível em: http://www.scielo.br/pdf/rbfis/v11n5/a07v11n5.pdf. Acesso em: 01 maio 2018.

OCDE. La definición y selección de competencias clave. Resumen ejecutivo. 2005. Disponível em:<www.oECD.org/edu/statistics/deseco>. Acesso em: 01 fev. 2018.

OLIVEIRA, Ronielton Rezende; MARTINS, Henrique Cordeiro; DIAS, Alexandre Teixeira. MONTEIRO, Plínio Rafael Reis. Uma proposta de instrumento de pesquisa para a avaliação do desempenho do escritório de gerenciamentos de projetos. Revista de Gestão e Projetos - GeP. Vol. 5, N. 1. Janeiro/Abril. 2014.

PARLAMENTO EUROPEU E CONSELHO. Recomendación del Parlamento Europeo y del Consejo sobre las competencias clave para el aprendizaje permanente, de 18 de dezembro de 2006. Diario Oficial de la Unión Europea, L394/310, 2006. Disponível em: https://eur-lex.europa.eu/legalcontent/ES/TXT/?uri=celex\%3A32006H0962. Acesso em: 12 fev. 2018.

PERRENOUD, P. Construir as competências desde a escola. Porto Alegre: Artmed, 1999.

PERRENOUD, P. Dez novas competências para ensinar: convite à viagem. Porto Alegre: Artmed, 2000.

SPRESSOLA, N. A. Instrumento para avaliar as competências no trabalho de tutoria na modalidade EAD. Dissertação (Mestrado em Engenharia de Produção) Escola de Engenharia de São Carlos, Universidade de São Paulo, São Carlos, 2010. Disponível em:< http://www.teses.usp.br/teses/disponiveis/18/18157/tde-11012011101157/publico/NilvaniaAparecidaSpressoladefinitiva.pdf>. Acesso em: 05 fev. 2018.

SCHNEIDER, DAISY. MP-CompEAD: modelo pedagógico baseado em competências para professores e para tutores em educação a distância. Porto Alegre: Universidade Federal do Rio Grande do Sul, Faculdade de Educação, 2014. Tese de doutorado. Disponível em: $<$ http://hdl.handle.net/10183/94705>. Acesso em: 20 fev. 2018.

VIVANCOS, J. Tratamiento de la información y competencia digital. Madrid: Alianza Editorial, 2010.

ZABALA, A.; ARNAU, L. Como aprender e ensinar competências. Porto Alegre: Artmed, 2010. 198p. 